\title{
CARTOGRAFANDO ESTRATÉGIAS DE RESISTÊNCIA CONSTRUÍDAS POR EDUCADORES NO COTIDIANO DE TRABALHO NUMA ESCOLA DE VITÓRIA-ES
}

\author{
Maria Elizabeth Barros de Barros \\ Danielle Vasconcelos Teixeira \\ Elizabeth Maria Andrade Aragão
}

Resumo: Este estudo buscou cartografar as estratégias de resistência construídas por professores de uma escola pública municipal de ensino infantil da cidade de Vitória, considerando a dinamicidade da produção de saúde e doença. A cartografia se efetivou por meio de vivência institucional, entrevistas, construção de um diário de campo, questionários, fotografias e confrontação-validação dos resultados com o coletivo de trabaIhadores. Apesar de todas as nocividades do ambiente de trabalho, os professores não se deixam paralisar e criam estratégias, novas formas de fazer seu trabalho, buscando condições menos adoecedoras para o desenvolvimento de suas atividades que, quando coletivizadas, potencializam o processo inventivo desses trabalhadores. Os resultados da pesquisa indicam a importância dessas discussões, uma vez que dão visibilidade a essas formas de luta, o que pode promover transformação do que é vivido nas escolas hoje.

Palavras-chave: Saúde.Trabalho. Educação. Resistência.

Este artigo refere-se a uma pesquisa que objetivou analisar o cotidiano de trabalho de uma escola pública municipal de ensino infantil de Vitória-ES. A motivação do trabalho se deu em função dos resultados de um estudo realiza- 
do em conjunto pelo Centro de Referência em Saúde do Trabalhador ${ }^{1}$ do Espírito Santo e o Núcleo de Estudos e Pesquisas em Subjetividade e Políticas da Universidade Federal do Espírito Santo vinculado ao Diretório de Grupos de Pesquisa do CNPq. A pesquisa evidenciou o quadro de precarização das condições de trabalho e de emprego vivenciado nas escolas públicas municipais, assim como o processo de adoecimento de professores que a organização do trabalho tem produzido no contemporâneo. Dentre seus resultados, sobressaíram, como fatores causadores do aumento da procura por serviços médicos por parte dos docentes e o conseqüente afastamento do trabalho durante o ano letivo: o estado de exaustão emocional, a insatisfação no desempenho das atividades diárias, o convívio em ambiente de trabalho estressante, as relações professor-aluno pautadas por permanentes e insolúveis conflitos, a diminuição de autonomia no planejamento curricular, o ritmo acelerado de trabaIho, a pressão da direção escolar, a carga horária de trabalho excessiva e a desqualificação profissional. Outros aspectos significativos destacados foram a perda crescente do controle do seu processo de trabalho e a dificuldade de reapropriação e reinvenção do próprio processo de trabalho.

Esses dados sinalizam a relevância da realização de estudos que priorizem a busca de compreensão sobre as nocividades do trabalho na escola e suas relações com a saúde dos trabalhadores no município de Vitória. Assim, a pesquisa que ora apresentamos inseriu-se nesse contexto. Objetivamos conhecer os processos de trabalho escolar na sua complexidade, partindo do princípio de que, para dar conta das variabilidades do trabalho e realizar as tarefas definidas na organização do trabaIho, os docentes alteram seus modos de operar afirmando o caráter processual e sempre inventivo da vida. Portanto o eixo central da pesquisa não girou em torno apenas do sofrimento provocado pelas situações de trabalho adversas à saúde. Priorizamos a apreensão e compreensão dos movimentos para criar e resistir, no seu duplo sentido - de recusa e de criação - ao que é nocivo à vida nos ambientes de trabalho. Focamos os movimentos efetivados pelos professores com o propósito de os aliançar com processos de produção de saúde. Essa decisão deveu-se à certeza de que, muitas vezes, ao naturalizar as estratégias de luta dos trabalhadores, as análises dos processos de trabalho limitam-se à abordagem de decisões individuais para a resolução de problemas pontuais e deixam de levar em conta as estratégias coletivizadas que sinalizam para o potencial de luta, de resistência ao que está instituído e, também, para o potencial de criação e invenção próprio dos viventes humanos.

1 Órgão público criado por uma parceria entre a Prefeitura Municipal de Vitória (PMV) e a Secretaria Estadual de Saúde (SESA) que desenvolve ações no campo da Saúde do Trabalhador dentro do espectro de atendimento do Sistema Único de Saúde (SUS). 
A cartografia dessas estratégias de resistência construídas pode ser um potente analisador para desfazer a tríade dor-desprazer-trabalho que não favorece a produção de saúde. Compartilhamos, portanto, os referenciais de análise que consideram que, para pensarmos a saúde do trabalhador, é preciso uma análise cuidadosa das relações de trabalho em sua dinâmica, em seu movimento.

Escolhemos, então, para compor nossa caixa de ferramentas conceitual-metodológicas as abordagens que tomam o trabalho como atividade, tal como o referencial da Ergologia (Yves Schwartz) e o da Clínica da atividade (Yves Clot), que buscam redimensionar uma tradição conceitual e metodológica pautada no paradigma da saúde ocupacional, que privilegia intervenções pontuais sobre os riscos à saúde. Aos trabaIhadores é imputada a responsabilidade e o ônus pelas doenças ocupacionais. Enfocamos, nesta pesquisa os processos de trabalho colocando em destaque sua complexidade, o trabalho em curso em suas diferentes situações, considerando seu aspecto processual.O centro do processo de trabalho não é nem o indivíduo nem o meio. Negamos um estatuto de relações dicotômicas entre trabalhador e trabalho, como pólos dados a priori. Dessa forma, a partir do conceito de atividade proposto pela Ergologia e pela Clínica da Atividade, tomamos os processos de trabalho considerando tudo que diz respeito ao sujeito, um trabalhador que é atravessado por valores, por paixões, por desejos, por suas experiências, por uma história.

Nesse aspecto, vale a consideração de que, a nosso ver, a lógica taylorista se impõe, muitas vezes, na escola pública, com a valorização de formas de gerenciamento escolar verticalizadas e burocratizadas, o que acaba por configurar uma organização do trabalho modelizadora que busca sobrecodificar modos de gerir a atividade que não favorecem a produção de criação. Um caminho na contramão do movimento da vida.

Diante do atual modelo de organização do trabalho e de educação, faz-se necessário compreender como o trabalho se coloca num contexto em que as políticas de educação adotadas, tentam minar as possibilidades de instituição de um sistema escolar pautado em modos cogestivos de trabalhar.

Partimos, então, de uma concepção segundo a qual o trabalho em educação não se reduz a programas, metodologias e tecnologias pedagógicas, mas, também, ao modo como se constrói a gestão dos processos político-organizacionais comprometidos com a produção dos atos de educar. Isso implica, certamente, tarefa tecnológica específica, ou seja, um certo jeito técnico de produzir educação indissociado de um determinado jogo de forças, valores, interesses dos diferentes atores e grupos da escola. Toda prática educacional envolve necessariamente o enfrentamento dos diferentes problemas produzidos na dinâmica escolar: quais problemas enfrentar? Como enfrentá-los? Ou seja, não pode- 
mos reduzir o trabalho em educação a uma questão "pedagógica".Tratase, principalmente, de encontros e confrontos de abordagens educacionais diferentes, disputas e acordos entre os diferentes atores que compõem o cenário escolar.

Assim, não é pelo fato de um grupo de trabalhadores se constituir formalmente como"gestores" da escola que os demais não tenham, também, governabilidade sobre os processos de trabalho, marcando com seu "governo" ${ }^{2}$ modo como se faz a gestão das práticas institucionais e pedagógicas/técnicas. Estamos afirmando que todos os atores da escola "governam" seus projetos de trabalho e, com essa finalidade, mobilizam uma infinidade de recursos para negociá-los com seus pares.

Foi nessa direção que privilegiamos o olhar. Ficamos atenta ao que se passava na escola estudada buscando analisar cada situação na sua singularidade, procurando apreender a forma como cada trabalhador constrói o mundo e a si mesmo, como se relaciona com os outros no processo de trabalho, como compõe alianças, lutas e pactuações que constituem o trabalho em situação.

Falamos, portanto, de trabalho como atividade, trabalho vivo que se efetiva nos dinamismos dos processos acionados pelos diferentes atores da escola. A existência do trabalho vivo, do trabalho concreto, em processual, que congrega nas suas diferentes singularidades muitos projetos de cunho "autonomista"-individualista, mas também uma dinâmica que desvela o trabalho coletivo que é exercido por todos os trabalhadores-docentes em espaços públicos nos quais as diferentes formas de gestão se efetivam.

Então, os diversos arranjos que se constituem nos ambientes laborais são territórios de tensões e, ao mesmo tempo, abertos a novos modos de fazer o trabalho quando se experimenta a emergência de processos instituintes que alteram os modos instituídos de educar. Nesse sentido, constatamos que os processos de trabalho revelam uma dinâmica instituinte que se abre a novas linhas de possibilidade no modo de se trabalhar em educação, o que permite a modificação dos processos de trabalho escolar. Concordamos com Barros e Galli (2004, p. 134) que afirmam que é preciso "interrogar e dar visibilidade a essa luta, muitas vezes, surda, que os trabalhadores travam nos processos de trabalho..., não para buscar uma forma ideal de trabalhar, mas para analisar os processos que estão em curso e construir, coletivamente, outras-novas formas de organização de trabalho".

2 Estamos aqui partindo das análises de Foucault (1979) que considera que, na modernidade, existem di ferentes níveis de governo: o governo político, o econômico e o moral. Esses níveis se dobram uns sobre os outros gerando uma arquitetura complexa, multivetorializada e contínua. 0 Estado não tem mais a primazia de foco ou de centro do poder, o que não significa desconsiderá-lo como um dos pontos de referência na constituição da governamentalidade multifocalizada. Referimo-nos, portanto, a uma arte de governar que não está apenas na máquina do Estado. 
O trabalho dos professores mostra vitalidade. Eles produzem sempre saídas para os imprevistos, para as adversidades, como falta de material, falta de apoio administrativo, condições salariais inadequadas, dentre outros aspectos. Em nossa pesquisa, buscamos compreender e dar visibilidade às formas como driblam essas situações. Em síntese, as estratégias de enfrentamento utilizadas-criadas e as formas como usam de si para produzir lutas por uma vida digna de ser vivida, uma luta por saúde. Os profissionais não são meros executores de prescrições ou de ordens preestabelecidas. Na luta que se trava muitas vezes de forma silenciosa, o trabalho docente mostra-se vivo e arredio à clausura dos processos inventivos. Os professores são capazes de singularizar parcialmente o trabalho que desenvolvem. Segundo Schwartz (2003), o trabalho como uso não é apenas aquele que é feito e exigido do trabalhador, mas também aquele que ele faz de si. Destacamos que essa autonomia é relativa, porque trabalhar implica também o uso de si por outros. É na negociação entre o uso de si por si e pelos outros que o trabalho produz algo, que há trabalho.

Essa forma de tratar o trabalho nos remete a uma concepção de saúde que não é compreendida como estado estável de bem-estar físico e mental e que negligencia a dimensão coletiva e política. Entendemos "saúde" não como ausência de doença, mas como possibilidade de criação de estratégias para que a vida possa ser potencializada. Criação de estratégias que envolvem um constante movimento de luta, um incessante jogo de forças, uma atividade. A doença, por sua vez, reflete necessariamente dificuldades de se alterar uma situação que produz sofrimento. Nesses termos, saúde não pode ser abordada tendo-se em vista apenas sua permanência ou conservação, pois se vincula à possibilidade de problematizar a vida cotidiana, de criar outras formas de estar no mundo. É lutar contra o que enfraquece, contra o que "tenta" nos imobilizar, porque nos exige o estrito cumprimento de princípios transformados em tarefas prescritas a serem executadas. É fato que as lutas do cotidiano não produzem necessariamente o adoecer, ao contrário, podem se constituir como possibilidades de escape à exploração do trabalho, à impotência diante dos modos de trabalhar que se impõem na escola. Podem incitar a criação de outras possibilidades de vida-trabalho.

A vida é criação, se expande para além da rigidez de normas e leis instituídas. Essa direção de análise proposta por Canguilhem (1990) considera

que para um ser vivo, o fato de reagir por uma doença a uma lesão, a uma infestação, a uma anarquia funcional, traduz um fato fundamental: é que a vida não é indiferente às condições nas quais ela é possível, que a vida é polaridade e por isso mesmo, posição inconsciente de valor, em resumo, que a vida é, de fato, uma atividade normativa.... No pleno sentido da palavra, normativo é o que institui as normas. (p.96) 
O planejamento e a prescrição do trabalho na escola também fazem parte desse movimento constitutivo da realidade escolar, mas não podem ser desconsiderados os imprevistos, os percalços que estão presentes onde há vida. Esses processos de trabalho na escola não são indiferentes à diversidade de experiências que nela se efetivam todos os dias. A cada dia, com certeza, novos problemas surgem, outras questões se colocam, experimenta-se um processo incessante de criação.

Quando analisamos a organização do trabalho dos docentes, percebemos que existe uma enorme distância entre o trabalho prescrito nos planejamentos pedagógicos e o trabalho efetivamente realizado pelos professores. A prescrição das tarefas diz respeito às regras preestabelecidas, definidas para que um determinado trabalho se realize, exigindo algo do trabalhador antes de o trabalho se concretizar. Em contrapartida, as situações de trabalho são dinâmicas e, portanto, o trabalho do professor inclui todos os recursos que ele próprio põe em funcionamento para que possa dar conta de sua pretensão de ensinar. Inclui as limitações da prescrição, a variabilidade do meio, os equívocos, a criação, as transgressões às regras, as frustrações, etc.

Nas situações de trabalho, é impossível que os indivíduos se detenham ao que lhes é prescrito. A vida e o trabalho como manifestação da vida escapam a qualquer tentativa de antecipação rígida. Os professores não se detêm nas tarefas que lhes são prescritas. Operam, contudo, de forma a chegar o mais próximo possível dos objetivos fixados por ela. Mas o que se tem feito com esses comportamentos que fogem às regras?

Os trabalhadores, mesmo taylorizados, escapam a qualquer tentativa de engessamento, pois, como humanos, precisam ser sujeitos de suas próprias normas. A imprevisibilidade deve ser gerida, não como uma execução, mas como um uso de si, o que significa dizer que é necessário recorrer a habilidades, recursos e escolhas para gerir essa imprevisibilidade.

Há, nas situações de trabalho, um vazio de normas (Schwartz, 2003), em que, em face às variabilidades, os indivíduos devem arbitrar e encontrar os meios para atingir (ou não) os objetivos fixados. Há um processo de retrabalho das regras, pois elas são insuficientes para dar conta de realizar o trabalho.

O conceito de atividade remete à demanda por renormatização e por inventividade e ao caráter não totalmente padronizável da vida-trabalho. $O$ trabalho é um lugar permanente de microescolhas e de debate de normas e valores. Atividade, por sua vez, é o ponto de partida para se pensar a saúde. Essa perspectiva busca analisar o trabalho dos professores levando em consideração o real da atividade que 
é igualmente aquilo que não se faz, o que se procura fazer sem lograr êxito o drama dos fracassos - aquilo que se teria querido ou podido fazer em outras situações. É necessário acrescentar aqui - paradoxo freqüente - aquilo que se faz para não fazer o que estar por fazer. Fazer é muito freqüentemente refazer ou desfazer. (Clot, 2001, p. 18)

Procuramos enfocar a atividade com a intenção de saber o que se passa neste intervalo entre as prescrições definidas para a realização do trabalho docente e o trabalho realizado. Trabalhar não é simplesmente aplicar regras. Incidentes fazem parte do dia-a-dia do trabalho dos professores e, para alcançar seus objetivos, os educadores empregam atividades de regulação que funcionam como gestão das variabilidades. Ao serem convocados no processo de trabalho, os professores "usam de si", constroem estratégias de acordo com o que lhes é exigido. É possível dizer que, a cada situação que se coloca, o professor elabora estratégias que desvelam a inteligência inerente ao trabalho humano e, portanto, é gestor do seu trabalho e produtor de saberes.

Tematizamos o trabalho partindo de abordagens que o afirmam como "atividade industriosa", ou seja, atividade que envolve sempre algo como um "debate de normas" (Schwartz, 2003), como criação. Essa noção implica, com base na herança de Canguilhem (1990), que há uma tendência de cada um renormatizar seu "meio de vida - trabalho". A atividade industriosa definida como um debate de normas significa considerar que é por meio dessas normas que podemos encontrar, dentre outras, a dimensão da gestão, incluindo (e aqui ressaltando) a gestão do próprio fazer.

Nessa direção, compreendemos trabalho como espaço concreto de invenção e reinvenção de regras e usos de si (Schwartz, 2000), e a gestão, como função de quem está produzindo e conduzindo seu próprio fazer. Entendemos que o modo de operar do trabalhador se confunde com o próprio processo de criação de si.Trabalhar-gerir inclui, também, a criação de formas-subjetividades à deriva, "outramento", corpos rebeldes que desejam a experimentação e o múltiplo, ou seja, trabalhadores que, no curso da atividade, criam permanentemente na relação com os instrumentos de trabalho, reinventando-se como trabalhador incessantemente; é "prática de tateio" (Kastrup, 1999). Estamos falando das maneiras como se produzem realidades, de jeitos de se produzir em situação de trabalho. Nossa preocupação é entender as articulações entre processos de subjetivação, modos de gestão e produção de saúde engendradas na escola estudada.

Então, no escopo desta pesquisa, consideramos que o trabalho pode ter repercussões danosas para o professor e, conseqüentemente, para o desenvolvimento de seu trabalho, na medida em que a prescrição realizada por setores de organização e os métodos utilizados na 
implementação das políticas de governo para a educação não conhecem a atividade efetivamente realizada por esses educadores e, portanto, não a consideram. Essa direção de análise afirma não os aspectos intra-subjetivos ou motivacionais do trabalhador, mas esse debate de normas, esse processo de criação de estratégias sempre presente nas situações de trabalho.

As maneiras como os indivíduos vivenciam suas experiências podem, muitas vezes, restringir os processos inventivos no trabalho de forma que as estratégias construídas, ao serem naturalizadas, não são percebidas como modos criadores que poderiam potencializar, no grupo, a construção de mecanismos que produzem saúde na escola. A pesquisa que passamos a apresentar visa, por esta via, a dar visibilidade às formas como os docentes de uma escola pública do município de Vitória-ES se defendem da nocividade do ambiente de trabalho, buscando potencializar o processo inventivo desses trabalhadores e, ao mesmo tempo, apoiar a criação de uma Comunidade Ampliada de Pesquisa ${ }^{3}$ na escola, fazendo com o que os resultados obtidos, a partir da metodologia de trabalho adotada, permitam aos educadores a realização de discussões sobre as estratégias criadas em frente às adversidades dos ambientes de trabalho e articulá-las a análises das políticas de governo que engendram uma determinada organização do trabalho. Buscamos compreender-transformar as relações entre o trabalho na escola e a saúde-doença desses educadores, a partir no diálogo-confrontação entre conhecimento científico e experiência dos trabalhadores, como nos indica a direção ergológica.

Nesse sentido, percebemos que o que produz saúde no trabalho é a possibilidade de luta como movimentos constitutivos da realidade. Acreditamos que, pela construção coletiva de novos sentidos para o vivido na escola, os professores poderão transformá-lo em um ambiente mais saudável onde os trabalhadores sejam os autores dessa mudança, articulando as políticas do cotidiano com o plano mais amplo dos projetos de governo para a educação municipal de Vitória da qual não pode ser dissociada.

\section{Da metodologia utilizada}

Quando buscamos conhecer as condições de trabalho da escola onde se efetivou a referida pesquisa, procuramos conhecer os trabalha-

3 Dispositivo de confrontação-cooperação entre conhecimento científico e experiência dos trabalhadores, "viabilizando a compreensão da importância do encontro dos trabalhadores com pesquisadores para que construam juntos novas possibilidades de saber, possibilitador da compreensão e intervenção em saúde, nos locais de trabalho. Trata-se de um diálogo crítico entre os saberes fundados na experiência prática dos trabalhadores (saberes 'informais') com o conhecimento científico (saberes'formais') de pesquisadores e profissionais de saúde." (Neves, Muniz, \& Silva, 2006, p. 6) 
dores/professores dessa escola, seu fazer, o uso de si que acionam para a realização do trabalho escolar.

Nessa direção, a metodologia de trabalho adotada consistiu basicamente em: entrevistas individuais, aplicação de questionário a todos os professores, vivência institucional, fotografia do ambiente de trabaIho e análise coletiva da atividade de trabalho.

A partir da vivência institucional, estratégia metodológica que permite acompanhar o traçado das forças que compõem as relações e a divisão social do trabalho, e utilizando a cartografia desses movimentos como método, foi possível traçar um plano de trabalho que pudesse dar visibilidade a algumas estratégias de resistência produzidas na escola. Partimos de Rolnik (1989), quando afirma que, "além dos movimentos de transformação das paisagens geográficas, as paisagens psicossociais também são cartografáveis" (p. 15). "A Cartografia", nesse caso, acompanha e se faz ao mesmo tempo que o desmanchamento de certos mundos - sua perda de sentido - e a formação de outros: mundos que se criam para expressar afetos contemporâneos, em relação aos quais os universos vigentes tornaram-se obsoletos. No entanto, seu caráter é circunstancial, na medida em que nos possibilita visualizar "os pontos de congelamento da capacidade normativa, os limites que urgem a experimentação, a intervenção que desestabiliza e articula fragmentos para a criação de novos territórios existenciais" (Passos \& Benevides, 2003, p. 2). Nesse sentido, a cartografia não permite separar descrição de funcionalidade, ou seja, no momento em que se descreve um fato, o colocamos a funcionar.

As entrevistas foram realizadas com seis professores de diversas turmas. Utilizamos entrevistas semi-estruturadas com 14 questões abertas previamente formuladas. Os diálogos foram todos gravados e transcritos, mediante consentimento dos entrevistados. As análises das transcrições constituíram um importante material que viabilizou maior conhecimento das formas como se efetivam estratégias de luta por saúde desses professores.

Outra direção metodológica utilizada foi a fotografia de cenas do cotidiano de trabalho na escola. Foram tiradas fotos da estrutura física da escola, do trabalho em sala de aula e de atividades extraclasse. A partir dessas imagens, foi possível discutir com os docentes as estratégias por eles utilizadas.

As fotografias são registros de uma marca das ações (Clot, 2006). Os mecanismos de produção da atividade de trabalho não são diretamente observáveis, entretanto acreditamos que a ação que pode ser discutida por meio das fotografias tem a possibilidade de se transformar noutra ação.

Consideramos as fotografias uma forma de acesso aos conflitos da atividade. Uma forma de nos utilizarmos desses debates sobre a ação 
que transformam no sujeito sua atividade. $O$ registro fotográfico da atividade realizada se mostra como uma opção metodológica bastante produtiva, uma vez que os próprios trabalhadores deixam de ser apenas observados para passar a serem observadores, co-autores na produção dos dados da pesquisa. As fotos se tornaram instrumentos para nossos interlocutores.

É por meio das imagens que podemos perceber que o real da atividade ultrapassa a tarefa e também a própria atividade realizada. Para Clot (2006), o real da atividade não compõe o que pode ser observado diretamente, é aquilo que se revela possível, impossível ou inesperado no contato com as realidades. Trata-se de um dispositivo por meio do qual os trabalhadores e os investigadores podem, então, começar a pensar coletivamente o trabalho para reorganizá-lo.

Optamos, também, por acrescentar procedimentos que pudessem se constituir como fonte de informações complementares, enriquecendo e conferindo uma maior consistência às discussões propostas. Assim, a partir do questionário $S R Q 20,{ }^{4}$ formulamos um novo questionário com o intuito de compreender o que os professores pensam sobre seu trabaIho na escola, suas nocividades, os efeitos dessas nocividades sobre sua saúde, suas estratégias para suportar/transformar tudo isso e suas sugestões para a melhoria do trabalho em educação. Por meio desses questionários, realizamos um inquérito no qual foi trabalhado o perfil sociodemográfico dos professores, a percepção sobre o ambiente de trabalho, os riscos, as fontes de tensão e cansaço, etc. As respostas ao questionário foram material importante na discussão sobre as condições de trabalho docente no Centro Municipal de Educação Infantil (CEMEI).

Partindo dos pressupostos conceitual-metodológicos indicados, criamos, como dispositivo de análise do trabalho, as rodas de conversa, quando foi possível dar visibilidade às estratégias de luta já existentes na escola e criar possibilidades para que fosse potencializada uma rede de pesquisas e transformação do ambiente escolar. Visamos a construir um diálogo entre a experiência dos trabalhadores e o saber científico, abrindo vias para uma luta por outras formas de vida e melhores condições de trabalho na escola. Os encontros com os educadores e a validação dos dados do questionário com os docentes foram registrados em fitas cassete e seu conteúdo foi transcrito para a análise do material construído.

\section{O que foi possível construir? Dos resultados produzidos}

Acreditamos ser importante não perde, como referência para análise do que foi produzido no processo investigativo, algumas informa-

4 Instrumento de trabalho da OMS que identifica transtornos mentais menores em grupos populacionais. 
ções sobre o funcionamento da escola. Esse CEMEl, localizado num dos bairros do município de Vitória, foi criado há três anos. É fruto da junção de turmas de educação infantil de algumas Escolas Municipais de Ensino Fundamental (EMEF) de uma mesma região, sub-região urbana, bem como da luta comunitária dos moradores dessa região.

Estudam na escola 650 alunos dos quais 325 estão matriculados no turno matutino e 325 no turno vespertino. Os alunos são divididos entre 13 turmas pela manhã e 13 turmas à tarde, cada uma com 25 alunos. A equipe técnica é composta por uma diretora e quatro supervisoras (duas por turno) que, concomitantemente, respondem pelas funções de pedagoga e coordenadora educacional.

A escola possui estrutura de madeira. Suas paredes são muito finas e as salas de aula bem próximas uma das outras. Uma delas possui janelas abertas para o refeitório da escola. Além disso, as salas de aula não têm teto direto, ou seja, não são fechadas na parte superior (Figuras 1 e 2). Essa estrutura facilita a dispersão de som por toda a escola. Os professores, para serem ouvidos, precisam falar muito alto.

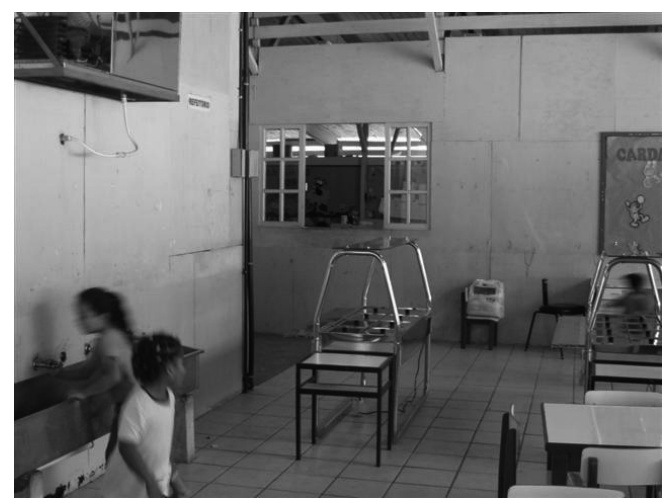

Figura 1. O refeitório da escola

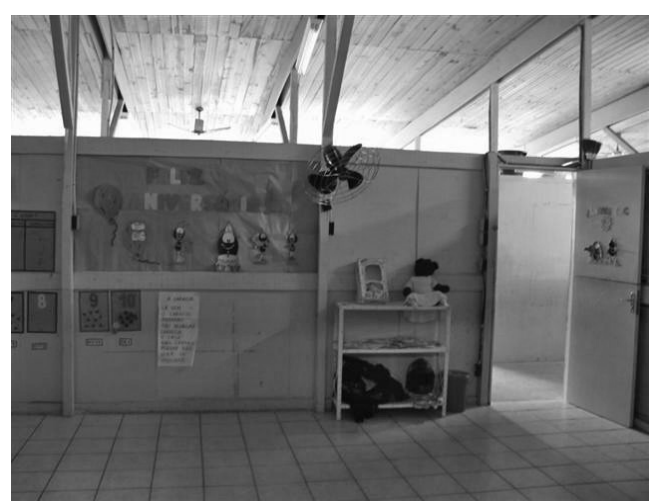

Figura 2. A estrutura da escola

Em função do barulho excessivo, muitas atividades de sala de aula são prejudicadas. Grande parte dos professores prefere realizar suas tarefas fora de sala de aula (Figuras 3 e 4). Algumas professoras relataram que, para conseguirem ensinar sem prejudicar sua voz, dividem a sala em grupos e se sentam com cada pequeno grupo de alunos para lhes explicar a matéria a ser realizada. 


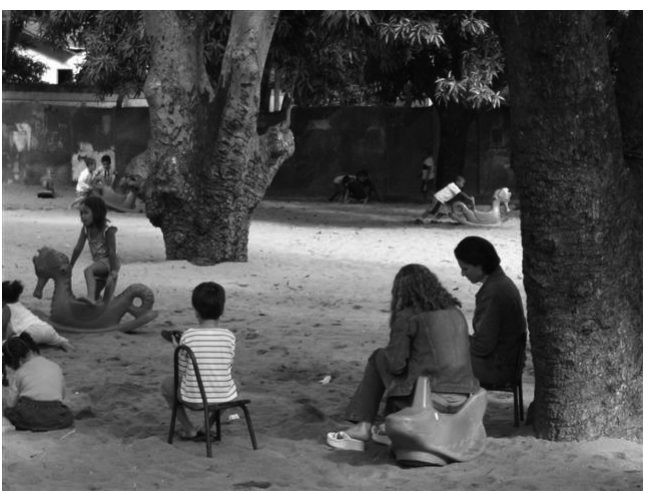

Figura 3. Atividade extraclasse no parque da escola

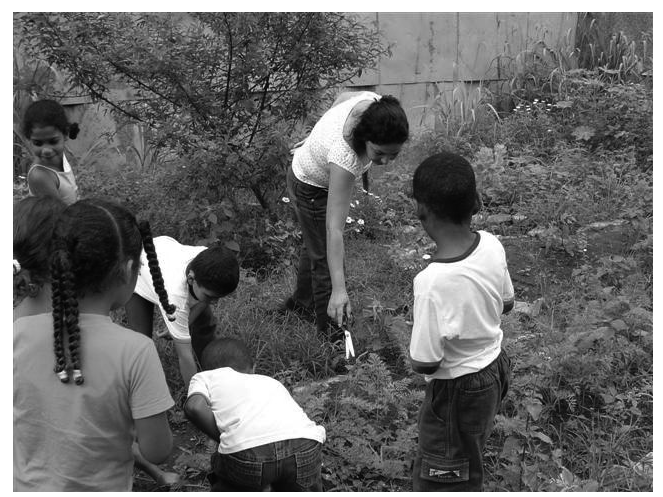

Figura 4. Atividade extraclasse na horta da escola

Do ponto de vista funcional,é possível identificar muitos movimentos por parte dos professores para que as aulas sejam mais "interessantes" para as crianças. Ao mesmo tempo, é visível as dificuldades que precisam buscar superar diariamente para cumprir o trabalho prescrito: salas de aula em locais improvisados; acústica não apropriada para uma sala de aula (muito ruído); presença de deficientes físicos na sala exigindo atenção diferenciada do professor; grande número de alunos por sala de aula; equipamentos físicos inapropriados que obrigam os professores a trabalharem curvados em função das cadeiras que são muito baixas (Figuras 5 e 6); temperatura alta nas salas de aula; iluminação insuficiente. As fotos mostram, também, os caminhos possíveis para o deslocamento do professor e a posição desconfortável diante da necessidade dos alunos por atenção individual.

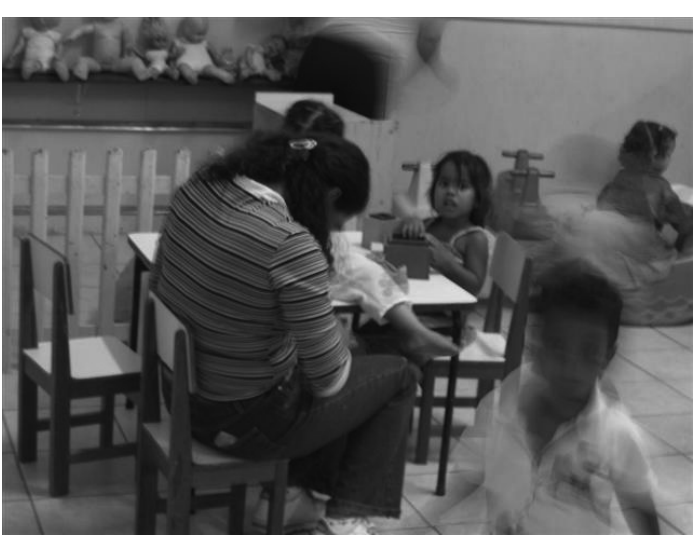

Figura 5. Professora curvada em posição desconfortável

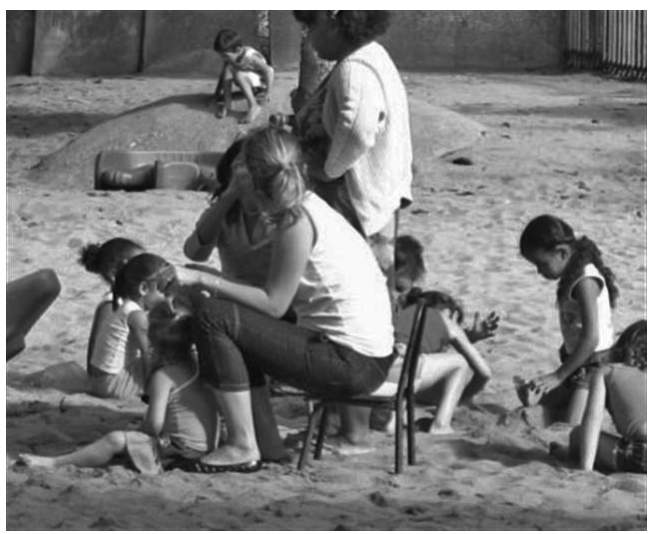

Figura 6.Professora sentada em cadeira muito baixa 
As professoras têm muita dificuldade em reunir os alunos para realizar algumas tarefas em meio à "bagunça" ${ }^{5} \mathrm{e}$ ao barulho. Uma das estratégias utilizadas pelos docentes, durante a entrada ou a saída dos alunos da sala de aula para o intervalo, por exemplo, é organizar os alunos em fila, em pares, e orientá-los a cantar enquanto se locomovem (Figura 7). Segundo comentam, a partir dessa proposição, precisam gritar menos com os alunos, que ficam menos dispersos, até chegarem a seus destinos.

Quando os alunos estão no parque, durante o intervalo, e as professoras precisam reuni-los para o retorno às salas, ao invés de gritar, forçando excessivamente a voz, elas se utilizam de estratégias, como bater palmas ou assoviar para chamar à atenção dos alunos.

Após a entrada e o intervalo, os alunos ficam muito agitados. Os níveis de barulho da escola tornam-se ainda mais intensos. Os professores, para não elevar demais a voz, trabalham, inicialmente, com atividades mais tranqüilas: colocam músicas calmas para os alunos cantar, distribuem livros com figuras, ou pedem para que realizem desenhos em silêncio, até que o nível de barulho da escola diminua.

Embora as regras afirmem o contrário, para facilitar seu trabalho durante o almoço, evitando carga excessiva de trabalho, os professores distribuem pratos para os alunos, que passam em fila para colocar a comida (Figura 8).

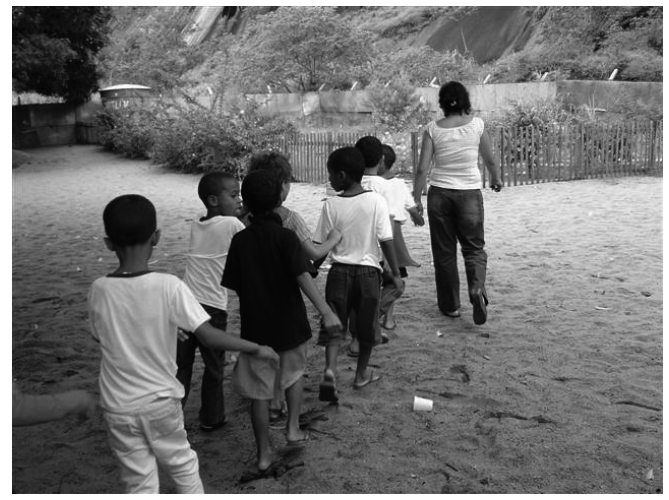

Figura 7. Estratégia da professora: alunos em fila

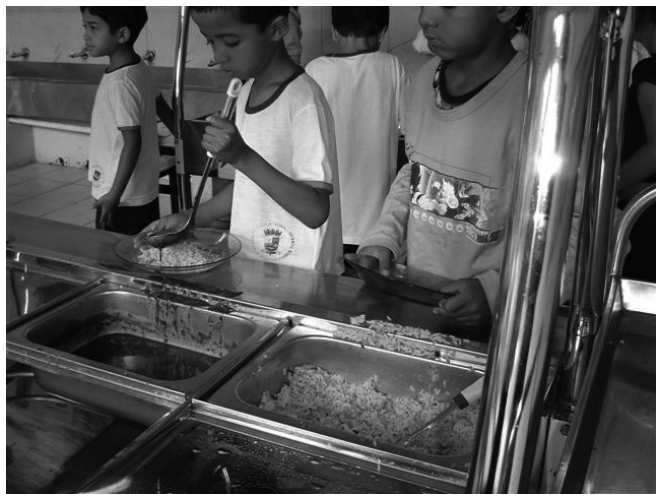

Figura 8. Alunos em fila, servindo seu próprio almoço

A seguir, apresentamos algumas falas das entrevistas com os professores, registradas no diário de campo, que dizem respeito à relação saúde-trabalho na escola.

5 Expressão utilizada pelos professores. 
Bem, logo que eu comecei a dar aula, uma situação que me incomodava muito era que a gente é instruída a trabalhar com roda. Eles dizem que, todos os dias, temos que colocar os alunos num círculo para trabalharmos com eles, rodinhas de conversa, e que temos que cantar todos os dias e contar histórias todos os dias. Mas, com todo esse barulho que tem aqui na escola, que você está vendo, fica impossível. Mas eu me adaptei e tirei essas coisas do meu programa... porque... se eu não fizer isso eu fico doida (Professora).

Nós não temos uma mesa e cadeira de acordo com a altura do professor, porque, de acordo com a nova proposta, o professor não pode sentar, deve estar se movimentando o tempo todo, apesar de que isso é complicado até certo ponto, porque, muitas vezes, o professor precisa estar sentando individualmente, ou com o aluno, até para estar atendendo ess a nova proposta de um atendimento mais individualizado. É claro que temos que ter muito cuidado, porque muitas vezes pode causar problemas de coluna. Eu tento mesclar o estar em pé e estar se abaixando para atender o aluno na mesa (Professora).

Nos momentos de barulho, eu procuro fazer um atendimento individualizado. Nos momentos de pico de barulho, tentar falar em grupo é você exigir da sua voz além do que ela pode agüentar, e pode provocar danos pro futuro. Então, você tem que aproveitar os horários de menor barulho para desenvolver trabalhos mais coletivos e depois trabalhar individualmente (Professora).

Durante a vivência institucional, foi possível perceber que o trabaIho dos professores é realizado num ritmo muito acelerado e sob forte pressão quanto ao tempo de conclusão das tarefas. Falam da "sobrecarga" de trabalho e da falta de tempo para se reunir discutir questões relacionadas com os aspectos da nocividade do trabalho, da saúde e do trabaIho:

O que acontece é que como não temos tempo para nada. Aproveitamos o horário que deveria ser para estudo dos professores (duas horas a cada 15 dias) para realizarmos reuniões de planejamento com a supervisora, para fazermos Conselho de Classe, para planejar algumas atividades e para fazer o que não dá tempo de ser feito mesmo (Professora).

Se você parar para pensar, a gente não se encontra. Tem colega aqui que nem se conhece direito. A gente nem tem intervalo conjunto, todos os professores. Aí a gente cria uns jeitos de conversar, de se ver, quando um vai para o intervalo mais cedo, e o outro demora mais um pouco para sair do intervalo, quando realizamos atividades conjuntas das turmas, na entrada, na saída, etc. Nós mesmos que criamos saídas, estratégias fora da rotina para se encontrar. Essas são as estratégias que a gente usa. Mas, se depender do sistema... o sistema não quer que nós nos encontremos, justamente para que... para que nós não possamos criticar (Professora). 
Os dados dos questionários apontam números importantes e preocupantes em relação à população estudada. A escola possui um quadro de 26 professores e, apesar de todos terem recebido um questionário, 18 foram devolvidos (69\%). Lembrando que todos os dados foram validados em uma reunião com os docentes, destacamos os aspectos relacionados com a caracterização da população estudada, conforme a tabela 1.

\section{Tabela 1}

Resumo - características dos professores

\begin{tabular}{|l|l|r|r|}
\cline { 2 - 3 } \multicolumn{2}{|c|}{} & $\mathbf{N}^{\circ}$ & $\%$ \\
\hline Local onde reside & Serra & 5 & 27,8 \\
& Vila Velha & 7 & 38,9 \\
& Cariacica & 2 & 11,1 \\
& Vitória & 4 & 22,2 \\
\cline { 2 - 4 } & Total & $\mathbf{1 8}$ & $\mathbf{1 0 0 , 0}$ \\
\hline Número de horas de trabalho no serviço doméstico & Nenhuma & 3 & 16,7 \\
& Menos de 4 horas & 2 & 11,1 \\
& De 4 a 10 horas & 3 & 16,7 \\
& De 11 a 20 horas & 5 & 27,7 \\
& De 21 a 30 horas & 2 & 11,1 \\
& De 31 a 40 horas & 0 & 0,0 \\
& De 41 a 50 horas & 0 & 0,0 \\
& Acima de 50 horas & 3 & 16,7 \\
\hline & Total & $\mathbf{1 8}$ & $\mathbf{1 0 0 , 0}$ \\
\hline
\end{tabular}


Tabela 2

Características dos professores

\begin{tabular}{|c|c|c|c|}
\hline & & $\mathbf{N}^{\circ}$ & $\%$ \\
\hline \multirow[t]{3}{*}{ Sexo } & Feminino & 18 & 100,0 \\
\hline & Masculino & 0 & 0,0 \\
\hline & Total & 18 & 100,0 \\
\hline \multirow[t]{3}{*}{ Trabalha no mesmo local de residência } & Sim & 4 & 22,2 \\
\hline & Não & 14 & 77,8 \\
\hline & Total & 18 & 100,0 \\
\hline \multirow[t]{8}{*}{ Número de horas semanais de trabalho público } & Menos de 4 horas & 0 & $\overline{0,0}$ \\
\hline & De 4 a 10 horas & 0 & 0,0 \\
\hline & De 11 a 20 horas & 1 & 5,6 \\
\hline & De 21 a 30 horas & 5 & 27,8 \\
\hline & De 31 a 40 horas & 2 & 11,1 \\
\hline & De 41 a 50 horas & 6 & 33,3 \\
\hline & Acima de 50 horas & 4 & 22,2 \\
\hline & Total & 18 & 100,0 \\
\hline \multirow{9}{*}{$\begin{array}{l}\text { Número de horas semanais trabalhadas no serviço } \\
\text { privado }\end{array}$} & Nenhuma & 15 & 83,3 \\
\hline & Menos de 4 horas & 0 & 0,0 \\
\hline & De 4 a 10 horas & 0 & 0,0 \\
\hline & De 11 a 20 horas & 0 & 0,0 \\
\hline & De 21 a 30 horas & 3 & 16,7 \\
\hline & De 31 a 40 horas & 0 & 0,0 \\
\hline & De 41 a 50 horas & 0 & 0,0 \\
\hline & Acima de 50 horas & 0 & 0,0 \\
\hline & Total & 18 & 100,0 \\
\hline \multirow{9}{*}{$\begin{array}{l}\text { Número de horas semanais trabalhadas como } \\
\text { autônomo }\end{array}$} & Nenhuma & 17 & 94,4 \\
\hline & Menos de 4 horas & 0 & 0,0 \\
\hline & De 4 a 10 horas & 0 & 0,0 \\
\hline & De 11 a 20 horas & 0 & 0,0 \\
\hline & De 21 a 30 horas & 1 & 5,6 \\
\hline & De 31 a 40 horas & 0 & 0,0 \\
\hline & De 41 a 50 horas & 0 & 0,0 \\
\hline & Acima de 50 horas & 0 & 0,0 \\
\hline & Total & 18 & 100,0 \\
\hline
\end{tabular}

No tocante à organização do trabalho, $44,40 \%$ informaram que recebem entre dois e três salários-mínimos por mês (Figura 9). 


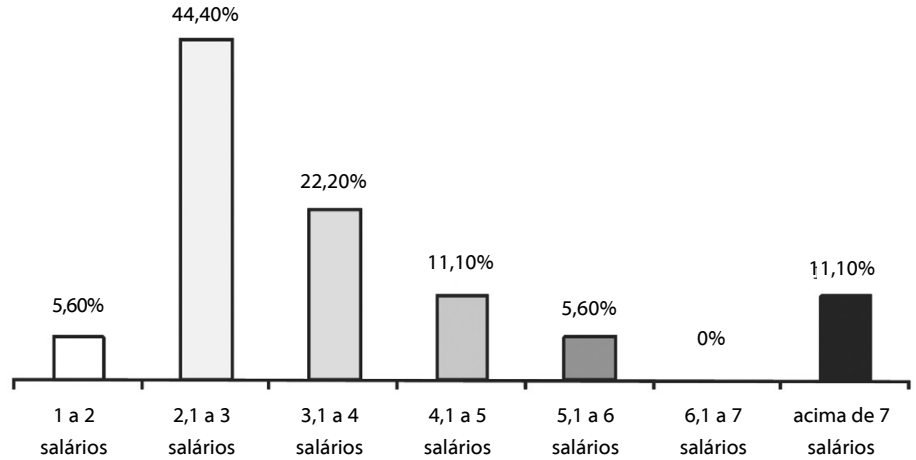

Figura 9. Renda mensal dos professores em salários-mínimos

A tabela 3, ainda sobre a organização do trabalho na escola, traz alguns resultados quanto a pausas realizadas e tempo para desenvolver todas as tarefas. Com relação ao tempo de descanso durante a jornada de trabalho, $61,1 \%$ informaram nunca fazer pausas, $27,8 \%$ disseram que fazem, às vezes, e $11,6 \%$ declararam que sempre ou quase sempre conseguem fazer pausas. Quanto ao tempo para realizar todas as tarefas em cada dia de trabalho, nenhum professor respondeu ter tempo mais do que suficiente. Apenas $16,7 \%$ disseram ter tempo suficiente, enquanto $38,9 \%$ dos professores responderam que o tempo é corrido e $44,4 \%$ informaram que o tempo para realizar todas as tarefas é insuficiente.

\section{Tabela 3}

Organização do Trabalho

\begin{tabular}{|l|l|r|r|}
\cline { 3 - 4 } \multicolumn{2}{|c|}{} & $\mathbf{N}^{\circ}$ & \multicolumn{1}{c|}{$\%$} \\
\hline Pausas durante o trabalho além & Sempre ou quase sempre & 2 & 11,1 \\
& Às vezes & 5 & 27,8 \\
& Nunca ou quase nunca & 11 & 61,1 \\
\cline { 2 - 4 } & Total & $\mathbf{1 8}$ & $\mathbf{1 0 0 , 0}$ \\
\hline Tempo para realizar todas as & Mais do que suficiente & 0 & 0,0 \\
tarefas em cada dia de trabalho & Suficiente & 3 & 16,7 \\
& Corrido & 7 & 38,9 \\
& Insuficiente & 8 & 44,4 \\
\cline { 2 - 4 } & Total & $\mathbf{1 8}$ & $\mathbf{1 0 0 , 0}$ \\
\hline
\end{tabular}


No tocante a afastamentos, $55 \%$ dos professores informaram já ter sofrido algum tipo de afastamento em função de questões referentes ao trabalho (Figura 10).

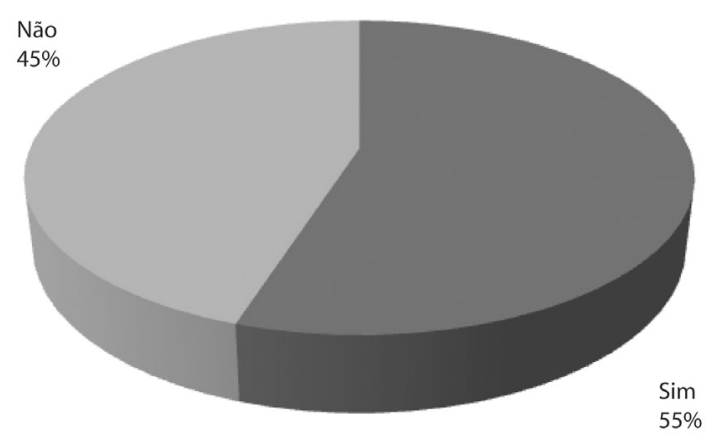

Figura 10. Adoecimento ou afastamento por doença relacionada com o trabalho

Em relação aos problemas associados à saúde, os transtornos foram agrupados com a seguinte freqüência: perda da voz $42,8 \%$; sinusite $14,2 \%$; conjuntivite $14,2 \%$; labirintite $14,2 \%$; infecções na garganta $14,2 \%$; dores nas articulações $14,2 \%$; e dores na coluna $14,2 \%$.

Quanto à pergunta sobre o caráter de suficiência das pausas para a recuperação do cansaço durante a jornada de trabalho, $61 \%$ dos professores responderam que as pausas nunca são suficientes, $33 \%$ afirmaram que às vezes são suficientes e $6 \%$ disseram que sempre são suficientes.

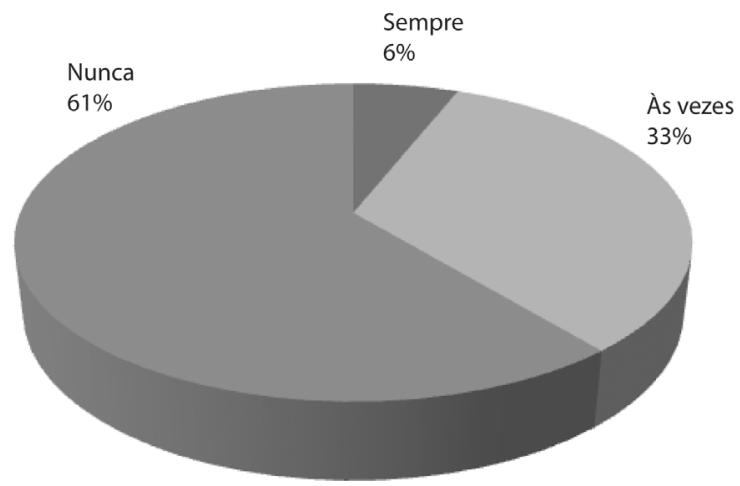

Figura 11. Caráter de suficiência das pausas para a recuperação do cansaço durante a jornada de trabalho 
Ainda sobre a organização do trabalho, os aspectos que mais agradam no exercício da função de educador são: ${ }^{6}$ contato com os alunos $66,6 \%$; relação com os colegas $44,4 \%$; prazer pelo que faz $27,7 \%$; e o ambiente físico de trabalho 9,0\% (conforme Figura 12).

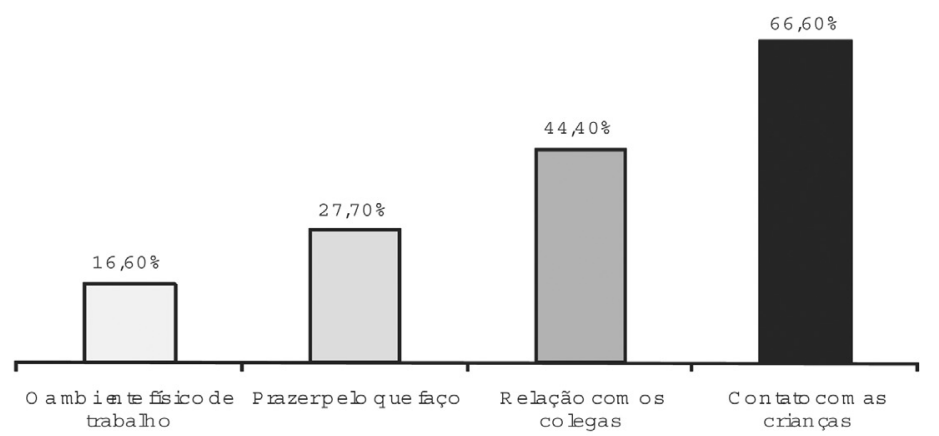

Figura 12. Fatores que mais agradam aos professores no seu trabalho

Já os aspectos que mais desagradam no exercício da função de educador são: falta de autonomia $(11,11 \%)$; desvalorização do professor $(11,11 \%)$; baixo salário $(11,11 \%)$; falta de tempo $(16,66 \%)$; falta de bom relacionamento entre os colegas $(27,77 \%)$; falta de recursos $(27,77 \%)$; e o ambiente físico de trabalho (50,00\%). (Figura 13).

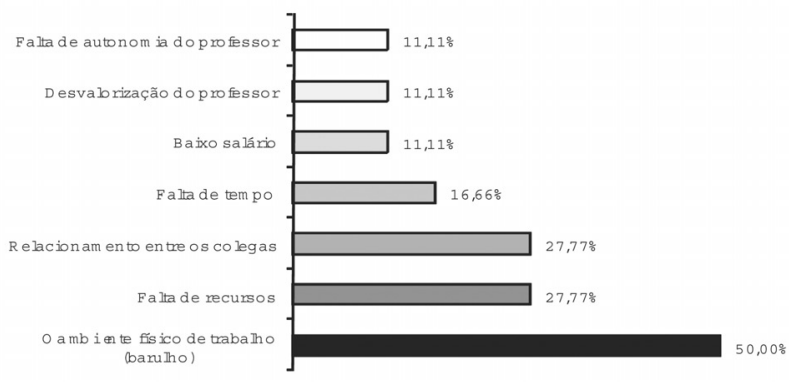

Figura 13. Fatores que mais desagradam aos professores no seu trabalho

A Figura 14 mostra as respostas dos professores, no tocante à iniciativa da Administração da escola, no sentido de ajudar na promoção de saúde do professor, porém $55 \%$ dos professores declaram não haver iniciativas nesse sentido.

6 De acordo com a proposta, optamos por um trazer um número maior de formas de manifestação do trabalhador, como diálogos, textos escritos, etc. 


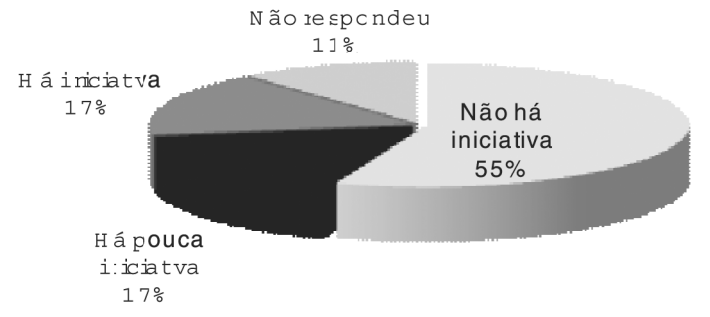

Figura 14. Iniciativa da Administração da escola no sentido de ajudar na promoção de saúde do professor

Seguem algumas respostas das questões abertas do questionário, ${ }^{1}$ no tocante à concepção dos professores sobre saúde e adoecimento. Estas são as respostas:

Adoecimento pra mim é quando nos encontramos impossibilitados de qualquer coisa, mas já consegui dar cinco horas de aula pra crianças de quatro anos, com 40 graus de febre e sem apoio de ninguém. Fui forte.

Adoecimento é não estar equilibrada ou incapacitada de desenvolver alguma função corporal...

Adoecimento é não conseguir trabalhar.

Adoecimento é qualquer interferência em nossa saúde que incomoda de alguma forma.

Ter saúde é sentir-se bem. É viver com ausência de distúrbios que afetem alguma área impedindo que a pessoa viva plenamente.

Saúde é ausência de doenças, é tudo de bom para qualquer pessoa.

Ter saúde é ter um perfeito funcionamento físico e mental, o perfeito estado de equilíbrio do corpo, estar sempre disposto; não precisar se ausentar de suas atividades. 
Ao serem perguntados sobre as situações de trabalho na escola que Ihes causam adoecimento e sobre as formas de enfrentá-las, os professores relataram aspectos de seu ambiente de trabalho e principalmente, as estratégias por eles criadas para transformá-lo em um ambiente mais saudável:

O espaço físico, a acústica ruim o que força os professores a aumentarem a voz. Para isso eu mudo minhas estratégias de trabalho.

O espaço físico, aparecimento de animais indesejáveis, móveis de crianças para serem usados por adulto. Eu me sento numa cadeira de criança. Barulho e giz também. É difícil, mas eu invento, improviso, substituo. O que não dá pra ser feito de um jeito, é feito de outro.

Excessivo uso de cloro nos ambientes durante o uso dos mesmos. Eu reclamo e quando dá, procuro manter distância, utilizando outros espaços para dar aula.

Procuro não usar muito o aparelho de som por causa do barulho, e procuro falar mais baixo. Converso com a direção para melhorarmos.

Evito ao máximo o uso do quadro-negro, pois tenho alergia.

Quanto à participação dos gestores-diretores-coordenadores na luta pela saúde do trabalhador, afirmaram:

Os gestores ajudam quando são solidários conosco em nossos problemas, porém, na escola, não se pára para discutir especificamente sobre a saúde do professor e, sim, sobre o aluno.

Quando se percebe que alguém não está bem, encaminham imediatamente para atendimento médico que fica próximo à escola. Além disso, não percebi nenhuma outra iniciativa.

Não há iniciativa. Pensa-se que só a gestão da escola deve ter a iniciativa, que isso tem que partir de cima. A saúde do professor, na verdade, nunca foi do interesse de ninguém. Ele tem que apenas estar na sala de aula, se está doente ou não, isso não importa. A parceria existe apenas quando há palestras. Isto é, quando há, é claro.

Em relação a possíveis mudanças no ambiente de trabalho, os professores anseiam por: dispor de mais tempo para atividades fora da sala de aula, utilização de lixeiras com pedal, limpeza das salas várias vezes durante o dia, obtenção de melhores brinquedos e materiais pedagógicos, diminuição da quantidade de alunos por turma, móveis adequados ao tamanho dos professores (cuja utilização freqüente lhes causa dores 
nas costas e nas articulações), uso de menos cloro em função de alergia a esse composto, melhor atendimento da SEME no trabalho com especificidades de alunos com necessidades especiais.

Durante o encontro com os professores para a validação dos resultados obtidos com o questionário e com as entrevistas, as discussões possibilitaram dar visibilidade às estratégias de luta por saúde produzidas por esses trabalhadores no cotidiano de trabalho:

Nunca pensamos nessa questão aqui na escola, pelo menos desde que atuo. O que a gente precisa urgentemente, é de um espaço para discutir essas questões aqui na escola. E o problema não é só aqui da escola, toda a categoria de professores nunca teve essa oportunidade.

é tudo muito disperso, ou porque muitas vezes nós não temos informação, ou porque não percebemos a extensão da gravidade. Não temos tempo para isso, somos absorvidos pelos compromissos e datas. A maioria das pessoas agüenta as conseqüências caladas, por medo de confrontar, porque você acaba ficando mal visto, sendo olhado de banda. Reunir os professores nessa luta é um trabaIho de conscientização.

na verdade, o que acontece é que os professores trabalham muito e falta tempo para estarem correndo atrás disso. Tem gente só corre atrás quando já está quase morrendo. Alguns fatores também atrapalham: o marasmo para se resolver às coisas, a falta de consciência do que é prejudicial à saúde, do que pode deixar seqüelas e determinar doenças graves no futuro.

É difícil porque não depende só da gente. A luta não pode ser só nossa. Tem que ter uma mudança em todo o sistema. Seria muito importante você voltar aqui na escola e apresentar esse trabalho do grupo porque é diferente quando a gente lutajunto.

Algumas considerações provisórias: um trabalho aberto a outras conexões

A pesquisa possibilitou a realização de uma cartografia das práticas de resistência construídas pelos professores da escola pesquisada, bem com a visibilidade de um modelo de organização de trabalho em educação que, ao exigir a execução das tarefas num tempo muito corrido, e com um excesso de prescrições, incita a minimização de possibilidades de criação dos docentes e produz danos à saúde, o que se traduz em um maior sofrimento patogênico.

Os docentes relatam que as prescrições endurecidas provocam um engessamento do processo de trabalho e concorrem para a restrição da potência de criação de outras possibilidades de vida-trabalho: 
Bem, logo que eu comecei a dar aula, uma situação que me incomodava muito era que a gente é instruída a trabalhar com roda. Eles dizem que todos os dias temos que colocar os alunos num círculo para trabalharmos com eles, rodinhas de conversa... que temos que cantar e contar histórias todos os dias. Mas, com todo esse barulho que tem aqui na escola, fica impossível... Mas eu me adaptei. Tirei essas coisas do meu programa, porque... Se eu não fizer isso eu fico doida.

Desconsiderando a variabilidade como aspecto do funcionamento da vida, os professores, tomam as imprevisibilidades como incapacidade individual. Destacam que se atualiza na escola uma forma de trabalho que não valoriza a autonomia e, além disso, restringe os espaços coletivos de análise do trabalho. Sinalizam para a necessidade de se instituir pausas maiores para a recuperação do cansaço durante a jornada de trabalho e a urgência de uma intervenção na estrutura física da escola.

As inumeráveis normas e prescrições instituídas tanto pela Secretaria Municipal quanto pela escola não dão conta dessa realidade complexa que se apresenta no cotidiano das escolas. Entretanto, como já afirmamos, é possível perceber que os professores reorganizam suas formas de trabalhar a partir das variabilidades e dos objetivos que trazem consigo. Buscam, como podem, criar um ambiente favorável para a realização de seu trabalho. Não se deixam estagnar diante das dificuldades, criam estratégias e novas maneiras de fazer o trabalho:

Nos momentos de barulho eu procuro fazer um atendimento individualizado, nos momentos de pico de barulho, tentar falar em grupo é você exigir da sua voz além do que ela pode agüentar, e pode provocar danos pro futuro. Então você tem que aproveitar os horários de menor barulho para desenvolver trabalhos mais coletivos, e depois trabalhar individualmente.

Eu invento, improviso, substituo. O que não dá pra ser feito de um jeito é feito de outro.

Ao mesmo tempo, não percebem que as estratégias criadas são formas de lutar contra o adoecimento provocado pelas nocividades do trabalho e consideram que a luta por condições de trabalho mais saudáveis somente ocorre por meio do sindicato ou por greves.

Eu acho que, pra mudar isso, o sindicato deveria estar mais presente, até para ver isso e denunciar. Lutar com a gente. Eles não vêm aqui.... Eles não lutam por isso.

Essa questão de greve a gente fica muito prejudicado.

Eu tento me adequar, a mudança parece que vai demorar. Talvez meu organismo se acostume!!! 
Não tem o que ser feito, reclamar todo dia é desgastante.

Não há por onde fugir, apenas trabalhar.

Como nos dizem Maturana e Varela (2001),"no âmago das dificuldades do homem atual, está seu desconhecimento do conhecer. Não é o conhecimento, mas sim o conhecimento do conhecimento, que cria o comprometimento" (p. 270). Nem sempre o trabalhador sabe que sabe e, nesse sentido, é importante dar visibilidade a essas formas de lutas, coletivizar esse conhecimento, potencializar a força de criação, de renormalização desses trabalhadores para que possam melhor enfrentar os desafios da atividade. A reclamação é a forma de contestação mais utilizada. Segundo Oddone (1986), para passar da fase de reclamação e denúncia para uma fase de controle da problemática saúde-trabalho, fazse necessário assegurar a participação ativa do grupo. De fato, é somente no ambiente de trabalho que se pode exercer, de modo contínuo e eficiente, uma ação de defesa do trabalho e da saúde do trabalhador.

A partir do encontro realizado, foram perceptíveis alguns aspectos importantes: os docentes começaram a dar visibilidade e importância ao saber que possuem, iniciaram um processo de se reconhecerem como um coletivo e, além disso, defrontaram-se com a valorização da autonomia como um aspecto essencial dos vivos. Como conseqüência ainda dessa coletivização, efetivaram proposições quanto à criação de outros movimentos de transformação do trabalho docente que não redundem no caráter autonomista e individualizado, mas, ao contrário, que sinalizem novas formas de enfrentamento. Pode-se dizer que o que não era ainda percebido como força entre os professores foi catalisado como potência de luta contra as imposições e prescrições rígidas do trabalho na escola. Então. foi possível observar o embrião da afirmação-criação de estratégias que necessariamente promove a desnaturalização da tríade dor-desprazer-trabalho. Assim se manifestaram alguns professores sobre essa questão:

O que a gente precisa urgentemente, é de um espaço para discutir essas questões aqui na escola. E o problema não é só aqui da escola, toda a categoria de professores nunca teve essa oportunidade.

É difícil porque não depende só da gente. A luta não pode ser só nossa. Tem que ter uma mudança em todo o sistema. Seria muito importante você voltar aqui na escola e apresentar esse trabalho da CAP, porque é diferente quando a gente luta junto.

De nossa parte, acreditamos que contribuímos para que os educadores se defrontassem com as estratégias de resistências que constroem no cotidiano para se manterem trabalhando. Instigamos o próprio co- 
nhecimento sobre saúde e, a partir dessa formulação, é possível que estejam mais bem preparados para discussões futuras sobre as condições e organização do trabalho na escola. Nosso foco centrou-se numa provoc(ação) dirigida aos trabalhadores com o intuito de acionar sua capacidade de criação, melhor dizendo, na consideração do trabalho como algo que é forjado pelos trabalhadores que criam para si perspectivas diversas. Nosso olhar privilegiou o modo como "usam de si" para efetivar mudanças nos ambientes de trabalho e se empenham nessa luta que, por sua vez,"é vivida como um jogo em que se batalha sempre para ganhar e não para perder" (Clot, 1999, p. 19). Isso não significa ignorar as dificuldades e dramas vividos no cotidiano das escolas, dramas vividos nas situações adversas de trabalho, mas é preciso analisá-los. A simples denúncia dessas situações não nos parece suficiente.Visamos a construir estratégias para fortalecer coletivos de trabalho em seus movimentos de ampliação de suas ações. Como nos diz Clot (1999), a partir de Odonne,"a tarefa consiste, então, em inventar ou reinventar os instrumentos dessa ação, não mais iniciando pelo protesto contra as pressões ou as 'negociando', mas pela via de sua superação concreta" (p. 23). Essa pretensão se materializou no processo investigativo.

\section{Mapping resistance strategies constructed by educators in the daily work in a school in Vitória-ES}

Abstract: This study mapped the strategies of resistance constructed by professors front to a harmful work, objectifying to to fortify these forms of confrontations and to collaborate for the transformation of the factors that intervene with the health of these educators. We mapped these movements that are put in functioning in school by means of: institutional experience, interviews, a construction of a diary, questionnaires, photography and confrontation of the results in the collective of workers. We perceive that although all the adversities, the teachers are not left to paralyze and they create proper strategies, new forms to make their work, searching less harmful conditions for their life. By making public these forms of confrontation, this research fortify the creative process of these workers and, at the same time, makes the results allow to the educators the accomplishment of quarrels on the bred strategies front to the adversities, making visible these forms of fight and fortifying the transformation of this reality.

Keywords: Health. Work. Education. Resistance. 


\section{Cartographiant les strategies de resistence construites par les educateurs dans le quotidien du travail dans une ecole dans la ville de Vitoria - ES}

Resume: Cette étude vise à cartographier les stratégies de résistence construites par les éducateurs d'une école publique d'enseignement pour enfants de Vitória-ES, considérant la dinamicité de la production de santé et de maladie. La cartographie est basée sur le vécu institutionnel au quotidien, des entretiens, de la constrution d'un journal d'activités, des enquêtes, des photographies et de la confrontation-validation des résultats avec le collectif des travailleurs. Malgré les aspects négatifs liés à l'ambiance de travail, les enseignants ne se découragent pas et ils créent de nouvelles stratégies pour travailler, en poursuivant des conditions de travail saines quand ils développent leurs activités. L'étude conclut qu'ils peuvent augmenter leur puissance et leur processus inventif en parlant collectivement de ces situations. Les résultats de la recherche indiquent l'importance de ces discussions pour éclaircir ces formes de lutte et rendre possible la transformation de ce qui est vécu dans les écoles aujourd'hui.

Mots clés: Santé. Travail. Éducation. Résistence.

\section{Cartografando estrategias de resistencia construídas por educadores em el cotidiano de trabajo de una escuela de Vitória - ES}

Resumen: Este estudio intentó cartografar las estrategias de resistencia construidas por docentes de una escuela pública de enseñanza de niños de la ciudad de Vitória, considerando la dinamicidad de la producción de salud y enfermedad. La cartografia se efectuó por medio de vivencia institucional, entrevistas, construcción de un diario de campo, cuestionarios, fotografías y un proceso de confrontación-validación de los resultados con el colectivo de trabajadores. A pesar de toda la nocividad del ambiente laboral, los docentes no se dejan paralizar y crean estratégias: nuevas formas de ejecutar su trabajo, buscando condiciones saludables para el desarollo de sus actividades que, cuando colectivizadas, potencían el proceso inventivo de esos trabajadores. Los resultados de la investigación indican la importancia de estas discusiones, pues dan visibilidad a esas formas de lucha, podendo hacer viables transformaciones de lo que es hoy vivido en las escuelas.

Palabras-clave: Salud.Trabajo. Educación. Resistencia. 


\section{Referências}

Barros, M. E. B., \& Fonseca, T. M. G. (2004). Psicologia e processos de trabaIho: um outro olhar. Revista Psico, 35(2), 133-140.

Canguilhem, G. (1990). O normal e o patológico. Rio de Janeiro:Vozes.

Clot, Y. (1999). La fonction psychologique du travail. Paris: PUF.

Clot,Y.(2001).Clínica do trabalho, clínica do real.Le journal des psychologues, (185). (Tradução para fins didáticos de Kátia Santorum e Suyaanna Linhales Barker. Revisãode Claudia Osório)

Dejours, C. (1994). Psicodinâmica do trabalho. São Paulo: Atlas.

Foucault, M. (1979). A governamentalidade. In M. Foucault, Microfísica do poder (pp. 277-293). São Paulo: Graal.

Kastrup, V. (1999). A invenção de si e do mundo: uma introdução do tempo e do coletivo no estudo da cognição. Campinas, SP: Papirus.

Maturana, H., \& Varela. F. (2001). A árvore do conhecimento: as bases biológicas da compreensão humana. São Paulo: Palas Athena.

Neves, M., Muniz, H., \& Silva, E. (2006). Comunidade ampliada de pesquisa: trabalhadores/as de escolas públicas compartilham saberes na busca da promoção da saúde nos locais de trabalho. Revista Eletrônica Extensão Cidadã, 2, 11.

Oddone, I. (1986). Ambiente de trabalho - a luta dos trabalhadores pela saúde. São Paulo: Hucitec.

Passos, E., \& Benevides, R. (2003). Políticas da transversalidade ou a transversalização como método clínico-político. São Paulo: Instituto Therapon.

Rolnik, S. (1989). Cartografia sentimental. São Paulo: Estação Liberdade.

Schwartz, Y. (2000). Trabalho e uso de si. Pro-Posições, (32), 13-44.

Schwartz, Y. (2003). Travail et gestion: niveaux, critéres, instances. Revue Performances Humaines et Technicque, 10-20. 
Maria Elizabeth Barros de Barros, Professora do Programa de Pós-Graduação em Psicologia Institucional e do Programa de Pós-Graduação em Educação da Universidade Federal do Espírito Santo (UFES). Centro de Ciências Humanas e Naturais. Departamento de Psicologia. Av. Fernando Ferrari, 514. Bairro: Goiabeiras. CEP: 29075910.Endereço eletrônico: betebarros@uol.com.br

Danielle Vasconcelos Teixeira, Mestranda do Programa de Pós-Graduação em Psicologia Institucional da Universidade Federal do Espírito Santo (UFES). Centro de Ciências Humanas e Naturais. Programa de Pós-Graduação em Psicologia Institucional (Mestranda). Av. Fernando Ferrari, 514, Goiabeiras, Vitória, Espírito Santo. CEP: 29075910. Endereço eletrônico: daniellevt@uol.com.br

Elizabeth Maria Andrade Aragão, Doutora, Professora do Programa de Pós-Graduação em Psicologia Institucional e do Programa de Pós-Graduação em Educação da Universidade Federal do Espírito Santo (UFES). Centro de Ciências Humanas e Naturais. Departamento de Psicologia. Av. Fernando Ferrari, 514 Bairro: Goiabeiras. CEP: 29075-910. Endereço eletrônico: baragao@terra.com.br

Recebido em: 27/01/2008

Aceito em: $21 / 10 / 2008$ 